УДК 621.924 .7

DOI https://doi.org/10.32838/2663-5941/2021.2-1/02

Залюбовський М.Г.

Відкритий міжнародний університет розвитку людини «Україна»

\title{
Панасюк I.B.
}

Навчально-науковий інститут інженерії та інформаційних технологій

Київського національного університету технологій та дизайну

Малишев В.В.

Інженерно-технологічний інститут

Відкритого міжнародного університету розвитку людини «Україна»

\section{МАШИНА ДЛЯ ОБРОБКИ ДЕТАЛЕЙ ІЗ КІНЕМАТИЧНОЮ ПАРОЮ ЧЕТВЕРТОГО КЛАСУ - КІНЕТОСТАТИЧНЕ ДОСЛІДЖЕННЯ}

Задля реалізації фінішних прочесів оздоблювально-зачищувальної обробки дрібних металевих та полімерних деталей застосовують різноманітні типи обладнання: вібраиійні машини та матини з обертовими смностями, шпиндельні та щіткові машини, а також машини зі складним просторовим рухом робочих ємностей. Найбільш перспективним типом галтувального обладнання вважають машини зі складним просторовим рухом робочих ємностей. Використання такого типу обладнання призводить до значного збільшення продуктивності виконання фінішних оздоблювально-зачишувальних операцій, ще зумовлено інтенсифікацією руху робочого масиву всередині ємностей. Відомі різні види машин зі складним просторовим рухом робочих ємностей із відмінними конструктивними та технологічними особливостями. Кожен вид машин зі складним просторовим рухом робочих ємностей потребує достеменного дослідження, в тому числі кінетостатичного. За допомогою системи автоматизованого проєктування SolidWorks виконано $3 D$-моделювання та подальше кінетостатичне дослідження машини для обробки деталей із кінематичною парою четвертого класу, яке полягає у визначенні та аналізі реакиій в усіх кінематичних парах просторового статично визначеного шарнірного механізму машини. Встановлено взаємозв'язок між зміною міжосьової відстані проміжного шатуна (робочої ємності) та максимальними значеннями реакцій у кінематичних парах машини. Максимальні значення осьових та радіальних складових реакиій у кожній кінематичній парі просторового механізму зростали зі збільшенням міжосьової відстані проміжного шатуна. Встановлено раціональний діапазон варіювання міжосьової відстані проміжного шатуна (робочої ємкості), що забезпечує утворення найменших значень реакцій в усіх кінематичних парах просторового шарнірного механізму машини під час ї̈ експлуатації за гранично допустимої кутової швидкості ведучого валу. Отримані результати досліджень можуть стати у нагоді в процесі проєктування відповідного галтувального обладнання з ємностями, що виконують складний просторовий рух.

Ключові слова: кінематична пара четвертого класу, просторовий шарнірний механізм, галтування, фінішні технологічні операщії.

Постановка проблеми. Задля реалізації фінішних процесів оздоблювально-зачищувальної обробки дрібних металевих та полімерних деталей, таких як відділення деталей від ливників [1, с. 10], полірування, шліфування [2, с. 25] та глянцювання, заокруглення гострих країв та очищення від продуктів корозії [3, с. 20-130] тощо, застосовують різні типи галтувального обладнання, в яких робочі ємності виконують складний просторовий рух [4, с. 18-21]. Попередньо було доведено, що використання таких типів обладнання сприяє підвищенню продуктивності та дає змогу значно скоротити час виконання відповід- них оздоблювально-зачищувальних технологічних операцій, призводить до зменшення енерговитрат [5, с. 150-174]. Авторами розроблений ряд машин зі складним просторовим рухом робочих ємностей із відмінними конструктивними та технологічними особливостями: машини 3 додатковими рухомими ланками [6, с. 55-62], машина 3 двома робочими ємностями, які з'єднані поступальною чи обертальною кінематичними парами, машина 3 додатковою рухомою ланкою - повзуном [7, с. 145], машини 3 видозміненими робочими ємностями [8, с. 70-12] тощо. Усі ці вдосконалення приймалися щодо «базової» конструкції машини, 
що була розроблена у 1966 році швейцарською фірмою Willy A. Bachofen (WAB) [9] та мала суттевий недолік - наявність пасивного зв'язку в кінематичному ланцюзі просторового шестиланкового механізму, який негативно впливає [10, с. 1040] на експлуатаційні властивості машини загалом. Удосконалення «базової» конструкції машини призводить до зміни конструктивних особливостей, збільшення ступеня рухомості просторового механізму, що своєю чергою впливає на утворення додаткової складової частини переміщення рухомих ланок механізму між собою з відповідною амплітудою. Таким чином, із метою раціонального використання розроблених конструкцій машин важливо виконати їх кінетостатичне дослідження задля визначення реакцій в усіх кінематичних парах просторового механізму, гранично допустимих значень міжосьових відстаней відповідних рухомих ланок, за якої реакції в кінематичних парах розроблених машин будуть перевищувати максимальні значення реакцій у кінематичних парах «базової» конструкції машини. Попередньо вже були проведені кінетостатичні дослідження деяких розроблених конструкцій машин $[11$, с. $14-16$; 12, с. 129-130]. Однак нині ще залишаються галтувальні конструкції машин, для яких не виконувалося відповідне кінетостатичне дослідження.

Постановка завдання. Метою роботи є кінетостатичне дослідження машини для обробки деталей із кінематичною парою четвертого класу, яке полягає у визначенні та аналізі реакцій в усіх кінематичних парах просторового шарнірного механізму машини за допомогою САПР SolidWorks, а також дослідження впливу зміни міжосьової відстані проміжного шатуна (робочої ємності) на максимальні значення реакцій у кінематичних парах машини.

Виклад основного матеріалу досліджень. Було розроблено конструкцію машини, в якій використовується кінематична пара четвертого класу, представлена на рис. 1. За допомогою кінематич-

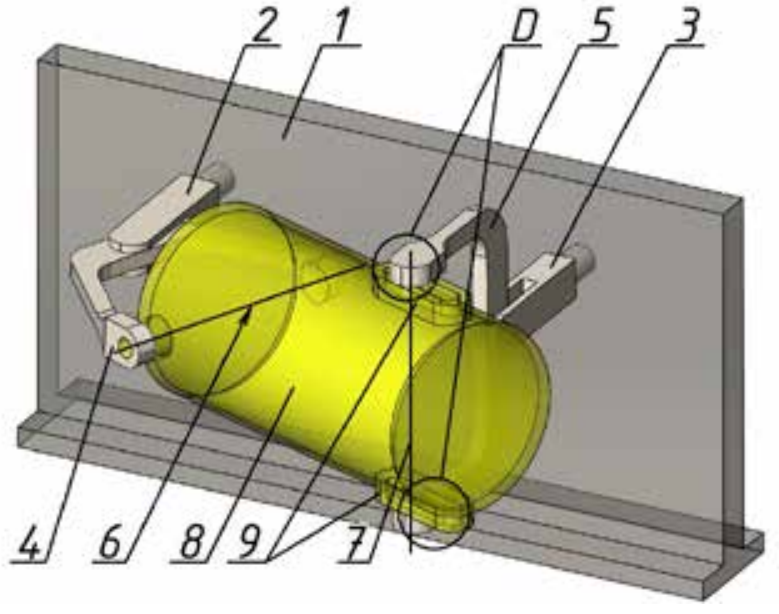

Рис. 1. Модель розробленої конструкції машини 3 кінематичною парою четвертого класу

ної пари четвертого класу між собою з'єднані ведений шатун та проміжний шатун (робоча ємкість). Основні геометричні та конструктивні параметри моделі машини 3 кінематичною парою четвертого класу, виконаної у САПР SolidWorks, приймалися аналогічними до параметрів промислового змішувача «Turbula T10B» («базова» конструкція машини). Ці геометричні параметри моделі машини представлені в таблиці 1.

Машина складається зі станини 1 , ведучого 2 та веденого 3 валів, які встановлені у станині паралельно в одній площині. Ведучий вал 2 кінематично 3'єднаний із ведучим шатуном 4, а ведений вал 3 - із веденим шатуном 5 . Діаметрально взаємоперпендикулярні вісі 6 та 7 ведучого шатуна 4 та веденого шатуна $5 €$ вісями кріплення проміжного шатуна 8 (робочої ємності). У цій конструкції машини ведений шатун 5 із проміжним шатуном 8 з'єднані за допомогою кінематичної пари четвертого класу $D$, усі інші кінематичні пари - обертальні п’ятого класу.

Iз використанням кінематичної пари четвертого класу ведений шатун 5 щодо проміжного

\begin{tabular}{|c|c|c|c|c|c|}
\hline \multirow{2}{*}{ Геометричний параметр машини } & \multicolumn{5}{|c|}{ Значення коефіцієнта $\Delta$} \\
\hline & 1,2 & 1,4 & 1,6 & 1,8 & 2,0 \\
\hline Діаметр робочої ємності $d_{P C}$ & \multicolumn{5}{|c|}{$0,318 \mathrm{~m}$} \\
\hline Довжина (між торцями) робочої ємності $l_{L}$ & $0,430 \mathrm{~m}$ & $0,480 \mathrm{~m}$ & $0,535 \mathrm{~m}$ & 0,590 м & $0,640 \mathrm{M}$ \\
\hline $\begin{array}{l}\text { Міжосьова відстань ведучого та веденого } \\
\text { шатунів } l_{\Psi(B)}\end{array}$ & \multicolumn{5}{|c|}{$0,272 \mathrm{м}$} \\
\hline Міжосьова відстань проміжного шатуна $l_{\text {Ш(пРом })}$ & $0,330 \mathrm{м}$ & $0,380 \mathrm{M}$ & $0,435 \mathrm{~m}$ & 0,490 м & $0,540 \mathrm{M}$ \\
\hline Об’єм робочої ємності $V_{P C}$ & $0,032 \mathrm{M}^{3}$ & $0,036 \mathrm{M}^{3}$ & $0,041 \mathrm{M}^{3}$ & $0,045 \mathrm{M}^{3}$ & $0,050 \mathrm{M}^{3}$ \\
\hline Маса усіх рухомих деталей машини $m_{D}$ & 49 кг & 51 кг & 52,6 кг & 54,0 кг & 55,5 кг \\
\hline Кутова швидкість ведучого валу машини $\omega_{\text {ве }}$ & \multicolumn{5}{|c|}{$3,3 \mathrm{c}^{-1}(32 \mathrm{oб} / \mathrm{xв})$} \\
\hline
\end{tabular}


шатуна 8 може виконувати не лише обертальне переміщення, а ще й додаткове зворотно-поступальне переміщення вздовж напрямних 9, які виконані на циліндричній поверхні проміжного шатуна 8 , у результаті чого можна варіювати відстань між протилежними торцями проміжного шатуна (робочої ємкості), цим самим впливати на зміну інтенсивності виконання відповідних галтувальних технологічних операцій.

Далі виконували дослідження, як зміна $l_{\text {Ш(Птом })}$ впливала на максимальні значення реакцій в усіх кінематичних парах машини, а також за досягнення якої міжосьової відстані проміжного шатуна $l_{\text {Ш(Пром) }}$ (утворюється між осями кріплення ведучого та веденого шатунів) реакції в кінематичних парах машини будуть перевищувати попередньо визначені в роботі [11, с. 15-17] максимальні значення реакцій у кінематичних парах «базової» конструкції машини. Силове дослідження проводилося із використанням САПР SolidWorks-2016. У САПР SolidWorks-2016 було сконструйовано модель машини зі змінним параметром - довжиною проміжного шатуна (робочої ємкості). Було утворено п'ять робочих ємностей із різною довжиною. Для кожної довжини проміжного шатуна (робочої ємкості) відповідним був коефіцієнт $\Delta(1,2 ; 1,4 ; 1,6 ; 1,8 ; 2,0)$, який раніше вже був запропонований у роботі $[5$, с. 87$]$ та характеризує відношення міжосьової відстані проміжного шатуна до міжосьової відстані ведучого чи веденого шатуна машини: $l_{\text {Ш(пРом })} / l_{\text {Ш(B) }}$. Таким чином, визначали реакції у всіх кінематичних парах машини із застосуванням проміжного шатуна (робочої ємності) різної довжини.

Кінетостатичне дослідження виконувалося під час роботи моделі машини на холостому ході (без завантаженого робочого середовища) за кутової швидкості ведучого валу $3,3 \mathrm{c}^{-1}$, оскільки попередні результати силового дослідження «базової» конструкції машини [11, с. 15-17] показали, що усі значення реакцій у кінематичних парах машини під час іiї роботи як на робочому ході, так і на холостому ході будуть пропорційно відрізнятися на однакове значення для будь-якого положення рухомих ланок (кута повороту ведучого валу машини).

Зазначена вище кутова швидкість ведучого валу для цього типорозміру машини $є$ граничною під час виконання різного роду галтувальних технологічних операцій, вона буде викликати виникнення найбільших інерційних навантажень у кінематичних парах просторового механізму машини.
Також визначали міжосьову відстань проміжного шатуна, подальше збільшення якої буде призводити до такого приросту реакцій у кінематичних парах машини, коли вони стануть перевищувати значення реакцій у кінематичних парах «базової» конструкції машини, а отже, використання такої конструкції машини буде нераціональним. Схематичне зображення векторів реакцій в усіх кінематичних парах просторового шарнірного механізму розробленої конструкції машини із кінематичною парою четвертого класу представлено на рис. 2.

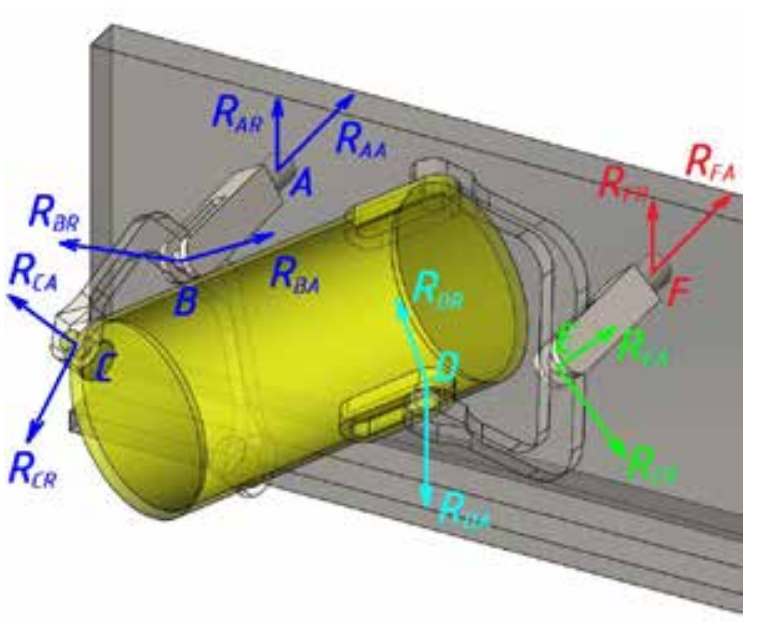

Рис. 2. Схема реакцій у кінематичних парах просторового механізму машини 3 кінематичною парою четвертого класу

Визначали максимальні значення реакцій $R$ у п'яти обертальних кінематичних парах п'ятого класу та одній кінематичній парі четвертого класу. Значення всіх реакцій були поділені на дві складові частини: радіальну та осьову: $R_{A A}$ - осьова складова частина реакції в кінематичній парі «станина - ведучий вал»; $R_{A R}$ - радіальна складова частина реакції в кінематичній парі «станина ведучий вал»; $R_{B A}$ - осьова складова частина реакції в кінематичній парі «ведучий вал - ведучий шатун»; $R_{B R}$ - радіальна складова частина реакції в кінематичній парі «ведучий вал - ведучий шатун»; $R_{C A}$ - осьова складова частина реакції в кінематичній парі «ведучий шатун - проміжний шатун»; $R_{C R}$ - радіальна складова частина реакції у кінематичній парі «ведучий шатун - проміжний шатун»; $R_{D A}$ - осьова складова частина реакції в кінематичній парі четвертого класу «проміжний шатун - ведений шатун»; $R_{D R}$ - радіальна складова частина реакції в кінематичній парі четвертого класу «проміжний шатун - ведений шатун»; $R_{E A}-$ осьова складова частина реакції в кінематичній 
парі «ведений шатун - ведений вал»; $R_{E R}$ - радіальна складова частина реакції в кінематичній парі «ведений шатун - ведений вал»; $R_{F A}$ - осьова складова частина реакції в кінематичній парі «ведений вал - станина; $R_{F R}$ - радіальна складова частина реакції в кінематичній парі «ведений вал - станина».

У таблиці 2 представлено визначені за допомогою САПР SolidWorks максимальні значення реакцій у кінематичних парах машини залежно від зміни коефіцієнта $\Delta$, а також попередньо 3'ясовані [11, с. 15-17] значення реакцій у відповідних кінематичних парах просторового механізму «базової» конструкції машини, що відповідає коефіцієнту $\Delta=1$.

На основі наведених у таблиці 2 результатів кінетостатичного дослідження було побудовано графіки залежності максимальних значень реакцій у кінематичних парах просторового механізму машини із кінематичною парою четвертого класу від зміни коефіцієнта $\Delta$, які наведені на рис. 3 (радіальні складові частини реакцій) та рис. 4 (осьові складові частини реакцій).

У конструкції машини із кінематичною парою четвертого класу при коефіцієнтах $\Delta=1,2$ та $\Delta=1,4$ максимальні значення реакцій практично у всіх кінематичних парах стали дещо меншими щодо максимальних значень реакцій у кінематичних парах «базової» конструкції машини. При коефіцієнті $\Delta=1,6$ вже більша половина максимальних значень реакцій у кінематичних парах досліджуваної конструкції машини вже значно перевищила максимальні значення реакцій, що виникають у кінематичних парах «базової» конструкції машини. Максимальне значення реакції $R_{F A}$ У два рази стало більше за максимальне значення реакції в аналогічній кінематичній парі «базової» конструкції машини.

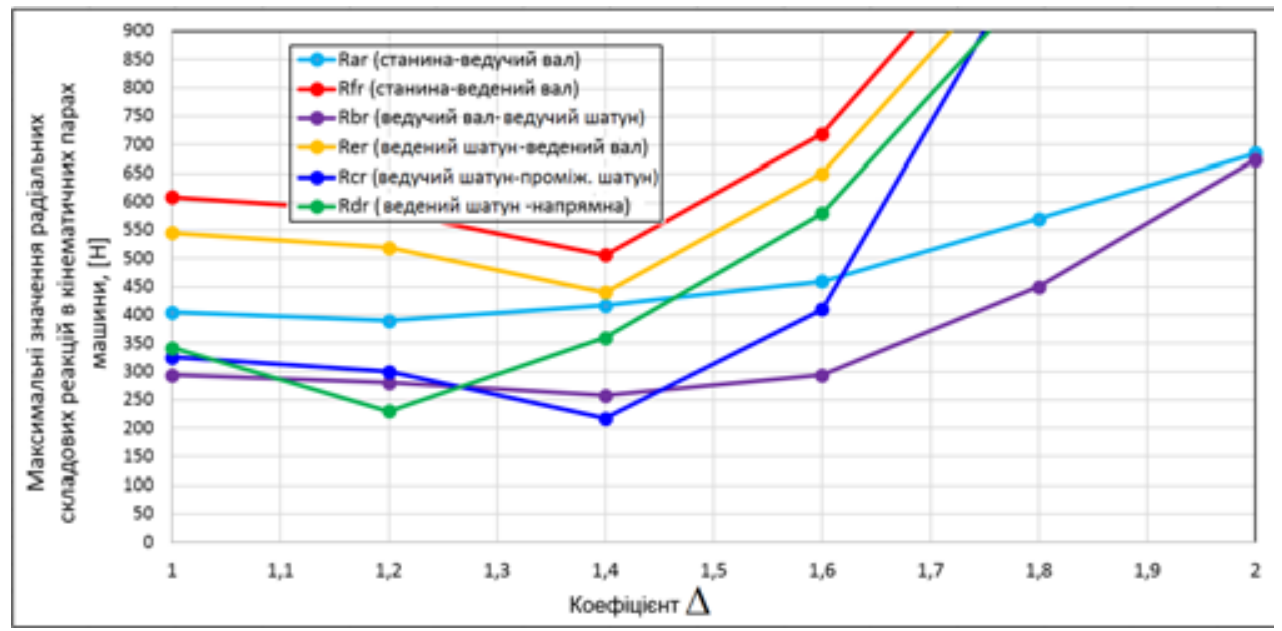

Рис. 3. Графік залежності максимальних значень радіальних реакцій у кінематичних парах просторового механізму від зміни коефіціснта $\Delta$

Таблиця 2

\begin{tabular}{|c|c|c|c|c|c|c|c|}
\hline & \multicolumn{6}{|c|}{ Коефіцієнт $\Delta$, що характеризує відношення $l_{\amalg(П Р О м)} / l_{\Psi(B)}$} \\
\hline & & 1,0 & 1,2 & 1,4 & 1,6 & 1,8 & 2,0 \\
\hline \multirow{12}{*}{$\begin{array}{c}\text { Значення } \\
\text { реакцій у } \\
\text { кінематичних } \\
\text { парах машини } \\
\text { під час їі } \\
\text { роботи на } \\
\text { холостому } \\
\text { ході }\end{array}$} & $R_{A A},[\mathrm{H}]$ & 88 & 98 & 138 & 195 & 420 & 593 \\
\hline & $R_{F A},[\mathrm{H}]$ & 68 & 96 & 144 & 218 & 480 & 660 \\
\hline & $R_{A R},[\mathrm{H}]$ & 405 & 390 & 417 & 460 & 570 & 685 \\
\hline & $R_{F R},[\mathrm{H}]$ & 608 & 582 & 506 & 719 & 1150 & 1598 \\
\hline & $R_{B A},[\mathrm{H}]$ & 198 & 123 & 120 & 123 & 164 & 192 \\
\hline & $R_{E A},[\mathrm{H}]$ & 124 & 90 & 118 & 168 & 258 & 370 \\
\hline & $R_{B R},[\mathrm{H}]$ & 294 & 280 & 258 & 294 & 450 & 674 \\
\hline & $R_{E R},[\mathrm{H}]$ & 545 & 519 & 440 & 650 & 1070 & 1485 \\
\hline & $R_{C A},[\mathrm{H}]$ & 95 & 79 & 91 & 167 & 278 & 405 \\
\hline & $R_{D A},[\mathrm{H}]$ & 194 & 180 & 145 & 125 & 133 & 198 \\
\hline & $R_{C R},[\mathrm{H}]$ & 325 & 300 & 217 & 410 & 1065 & 1310 \\
\hline & $R_{D R},[\mathrm{H}]$ & 342 & 230 & 360 & 580 & 995 & 1418 \\
\hline
\end{tabular}




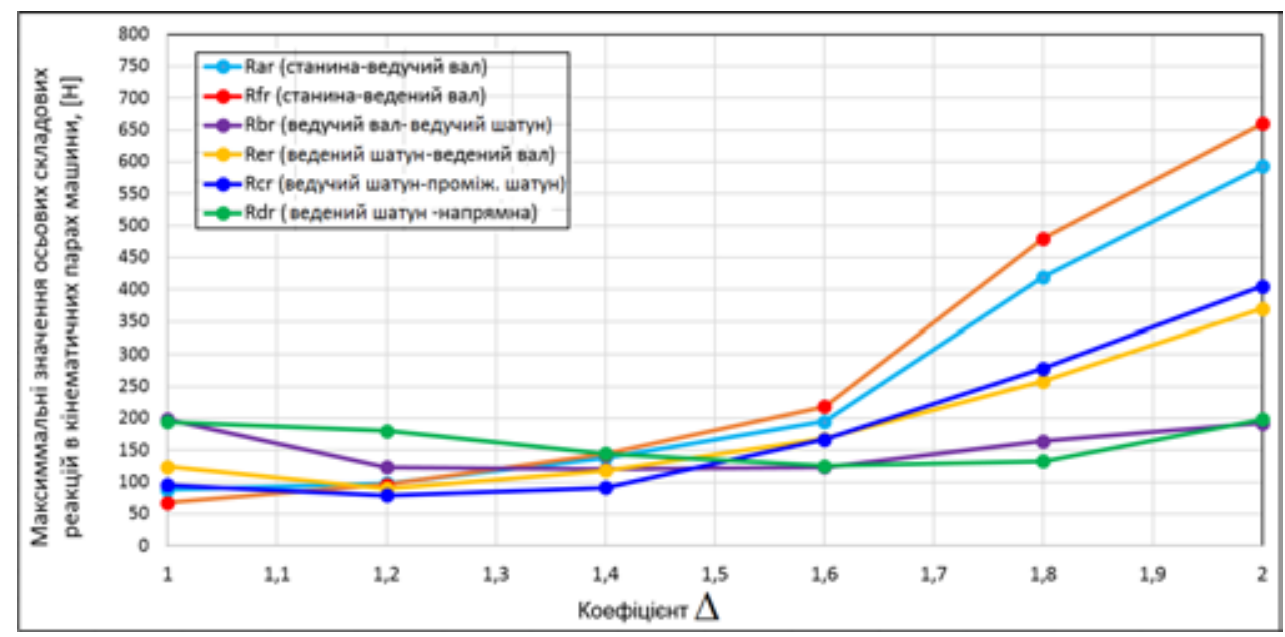

Рис. 4. Графік залежності максимальних значень осьових реакцій у кінематичних парах просторового механізму від зміни коефіцієнта $\Delta$

Висновки. Проведено кінетостатичне дослідження машини для обробки деталей із кінематичною парою четвертого класу, визначено реакції у п’яти обертальних кінематичних парах п’ятого класу та одній кінематичній парі четвертого класу просторового шарнірного механізму машини за допомогою САПР SolidWorks.

Досліджено вплив зміни відстані між протилежними торцями робочої ємності, який виражається коефіцієнтом $\Delta$, на приріст макси- мальних значень реакцій у кінематичних парах машини.

Встановлено, що досліджувану конструкцію машини раціонально використовувати в діапазоні зміни коефіцієнта $\Delta=[1,0-1,5]$. При коефіцієнті $\Delta$, що дорівнює 1,6, спостерігалося значне збільшення максимальних значень більшості реакцій порівняно 3 максимальними значеннями реакцій у кінематичних парах «базової» конструкції машини.

\section{Список літератури:}

1. Залюбовський М.Г., Панасюк І.В., Малишев В.В. Аналітичне визначення часу виконання технологічної операції відділення металевих деталей замка «блискавка» від ливників. Вісник Київського нащіонального університету технологій та дизайну. 2019. № 6 (140). С. 9-18.

2. Zalyubovskyi M.G., Panasyuk I.V., Smirnov Y.I., Klaptsov Y.V., Malyshev V.V. Experimental investigation of the handling process of polymeric units in a machine with a compacted space movement of working capacity. Bulletin of the Kyiv National University of Technologies and Design. 2019. № 2. P. 24-32.

3. Бурмістенков О.П. Виробництво литих деталей та виробів з полімерних матеріалів у взуттєвій та шкіргалантерейній промисловості : монографія / Під заг. ред. В.П. Коновала. Хмельницький : ХНУ, 2007. $255 \mathrm{c}$.

4. Marigo M., Cairns D. L., Davies M., Ingram A., Stitt E. H. Developing Mechanistic Understanding of Granular Behaviour in Complex Moving Geometry using the Discrete Element Method. Part B: Investigation of Flow and Mixing in the Turbula mixer. Powder Technology. 2011. Vol. 212. P. 17-24.

5. Залюбовський М.Г., Панасюк І.В., Малишев В.В. Машини зі складним рухом робочих ємкостей для обробки полімерних деталей: монографія. Київ: Університет «Україна», 2018. 228 с.

6. Zalyubovskii M.G., Panasyuk I.V. On the study of the basic design parameters of a seven-link Spatial mechanism of a part processing machine. International Applied Mechanics, 2020. 56, issue 1, 54-64.

7. Решетов Л.Н. Конструирование рациональных механизмов. Изд. 2-е, переработ. и доп. Москва : Машиностроение, $1972.256 \mathrm{c}$.

8. Zaliubovskyi M.G., Panasiuk I.V., Smirnov Yu.I., Malyshev V.V. Synthesis and research of the tumbling machine spatial mechanism. Naukovyi Visnyk Natsionalnoho Hirnychoho Universytetu. 2020. No. 178, issue 4. P. 69-75.

9. Willy A. Bachofen (WAB): сайт Willy A. Bachofen AG, Maschinenfabrik. - 2020. URL: https://www. wab-group.com/en/ (дата відвідування: 08.12.2020).

10. Antonyuk E.Ya., Sakhamov V.A., Koval N.I. Dynamic system of an engine with spatially rocking links: a mathematical model. International Applied Mechanics, 2010, 46, No. 9, P. 1039-1049. 
11. Залюбовський М.Г., Панасюк І.В., Малишев В.В. Силове дослідження просторового шестиланкового механізму машини для обробки деталей (частина 1: дослідження при роботі машини на холостому ході). Вчені записки Таврійського національного університету імені В.I. Вернадського. Серія: технічні науки. 2020. № 5, том 31 (70). С. 13-18.

12. Залюбовський М.Г., Панасюк І.В. Силове дослідження просторового семиланкового механізму машини для обробки деталей. Вісник Хмельницького національного університету. Технічні науки. 2020. № 4. С. 127-133.

\section{Zalyubovskyi M.G., Panasyuk I.V., Malyshev V.V. MACHINE FOR PROCESSING PARTS WITH A KINEMATIC STEAM OF THE FOURTH CLASS - KINETOSTATIC RESEARCH}

Various types of equipment are used to implement the finishing processes of finishing and polishing of small metal and polymer parts: vibration machines and machines with rotating containers, spindle and brush machines, as well as machines with complex spatial movement of working containers. The most promising type of tumbling equipment are machines with a complex spatial movement of working containers. The use of this type of equipment leads to a significant increase in the productivity of finishing finishing and stripping operations, which is due to the intensification of the movement of the working array inside the tanks. Known are various types of machines with complex spatial movement of working containers with different design and technological features. Each type of machine with a complex spatial movement of working containers requires detailed research, including kinetostatic research. With the help of the SolidWorks computer-aided design system, 3D modeling and further kinetostatic research of a machine for processing parts with a kinematic pair of the fourth class was carried out, which consists in determining and analyzing the reactions in all kinematic pairs of a spatial statically determined hinge mechanism of the machine. The relationship between the change in the center distance of the intermediate connecting rod (working capacity) and the maximum values of the reactions in the kinematic pairs of the machine has been established. The maximum values of the axial and radial components of the reactions in each kinematic pair of the spatial mechanism increased with an increase in the center distance of the intermediate connecting rod. The rational range of variation by the center distance of the intermediate connecting rod (working capacity) has been determined, which ensures the formation of the lowest reaction values in all kinematic pairs of the spatial hinge mechanism of the machine during its operation at the maximum permissible angular velocity of the drive shaft. The obtained research results can be useful in the design of appropriate tumbling equipment with containers that perform complex spatial motion.

Key words: kinematic pair of the fourth class, spatial hinge mechanism, tumbling, finishing technological operations. 